\title{
Rethinking the poverty-disease nexus: the case of HIV/AIDS in South Africa
}

Journal of Medical Humanities, early online, pp. 1-18:

http://link.springer.com/article/10.1007\%2Fs10912-015-9369-x

\author{
Kiran Pienaar \\ National Drug Research Institute, Curtin University, Melbourne, Australia. \\ Phone: +61 390792204
}

Email: kiran.pienaar@curtin.edu.au

\begin{abstract}
While it is well-established that poverty and disease are intimately connected, the nature of this connection and the role of poverty in disease causation remains contested in scientific and social studies of disease. Using the case of HIV/AIDS in South Africa and drawing on a theoretically grounded analysis, this paper reconceptualises disease and poverty as ontologically entangled. In the context of the South African HIV epidemic, this rethinking of the poverty-disease dynamic enables an account of how social forces such as poverty become embodied in the very substance of disease to produce ontologies of HIV/AIDS unique to South Africa.
\end{abstract}

Keywords: HIV/AIDS and poverty; ontologies of disease; Science and Technology Studies; biological/social dualism 


\section{Introduction}

The world's biggest killer and the greatest cause of ill health and suffering across the globe, including South Africa, is extreme poverty [...] As I listened and heard the whole story told about our own country, it seemed to me that we could not blame everything on a single virus [HIV]. It seemed to me also that every living African, whether in good or ill health, is prey to many enemies of health that would interact one upon the other in many ways, within one human body.

Thabo Mbeki (2000b), former President of South Africa

Only HIV predicts AIDS [...] No other factor on its own, including drug use, diet or poverty, is sufficient to cause AIDS.

Nathan Geffen (2006), South African HIV activist

Few issues define contemporary South Africa as forcefully as HIV/AIDS. ${ }^{1}$ This is, of course, partly because South Africa has the largest HIV epidemic in the world (UNAIDS 2012). However, it is also because HIV/AIDS has been a source of conflict in post-apartheid South Africa, generating a series of public disputes and legal battles over the science of HIV and the best form of treatment. The conflict is closely connected to former President Mbeki's approach to HIV/AIDS. Mbeki (in)famously questioned the scientific orthodoxy on HIV/AIDS, insisting that AIDS is a disease of poverty and not simply the outcome of a viral infection. The account of AIDS that he proposed treats disease as the product of social forces, notably poverty. Mbeki's 
dissident views were endorsed by a small, powerful group of loyalists in the ruling African National Congress (ANC), including the then Health Minister, Mantombazana Tshabala-Msimang (Youdé 2007). Like Mbeki, Tshabalala-Msimang was skeptical about the efficacy of anti-retroviral drugs, raising concerns about their toxicity and their potentially harmful long-term impact (Tshabalala-Msimang 1999). Because of these concerns, the Mbeki government was reluctant to adopt a public sector anti-retroviral therapy (ART) program, stressing instead the value of an HIV policy that focussed on prevention, poverty alleviation, palliative care, traditional medicine, and nutritional interventions (Butler 2005). Consequently, it was only in 2003 - twenty-one years after the first cases of HIV were diagnosed in South Africa - that the national government approved a plan to deliver universal ART (Low et al. 2010). South Africa's policy shift to an emphasis on ART provision is evident in the second National Strategic Plan (NSP) on HIV (2007-2011), which set a target of 80\% HIV-treatment coverage (Simelela and Venter 2014). By the end of 2010, actual coverage rates fell far short of this target with treatment reaching only $55 \%$ of those needing it (McNeil n.d.). In response to this gap in treatment access, South Africa's current NSP for 2012-2016 features a larger budget for treatment to ensure that the $80 \%$ target is reached by 2016 (McNeil n.d.). Although this target still does not meet the goal of universal ART coverage, it marks a sustained shift from Mbeki's AIDS dissident policy approach, which contained no provisions for a public ART program.

Mbeki's dissident views attracted strong criticism both from the international AIDS activist community and from South African civil society, notably from prominent local HIV/AIDS organisation, the Treatment Action Campaign (TAC). With more than 16,000 members and 276 branches countrywide, TAC is the largest, South 
African non-governmental organization (NGO) for people living with HIV (Peacock, Budaza, and Greig 2008). TAC leaders contested the government's claim that AIDS in Africa is a symptom of endemic poverty, arguing that poverty is a distal factor that shapes the disease, but not its primary causal agent. Instead, they endorsed the orthodox scientific explanation that AIDS is caused by the virus, HIV. In much of the scholarly literature on the TAC-government struggle, these two accounts of AIDS causation have been treated as polarised along orthodox/dissident lines (see for example, Butler 2005, Schneider 2002, Wang 2004). Against the commonplace view that the accounts of AIDS offered by the TAC and the Mbeki government were irreconcilably different, this paper draws attention to an important (and worrisome) similarity they share. Both accounts, I suggest, reduce AIDS to a matter of fact: a fixed object that is either the product of biological forces (a viral infection) or the product of social forces (poverty). Yet, as I will argue, disease exceeds any notion of simple fact, whether facts are construed as effects of biological or social forces. Indeed, the complexities of HIV/AIDS in South Africa and the continually changing character of the epidemic suggest the need for a new conceptual approach, one which treats the facts of disease as temporary and contingent, rather than stable and foundational.

This paper offers an initial contribution to addressing this need. It draws on concepts from science and technology studies (STS) to present a theoretically grounded analysis of HIV/AIDS in South Africa, examining in particular the ways in which the disease and its facts are constituted. Importantly, and in contrast to the government and TAC's view of disease as a fixed and stable entity, possessed of intrinsic characteristics, I argue that disease is emergent and open to change. Its ontology is forged through, rather than preceding, its encounters with political and social 
phenomena such as poverty, underdevelopment and entrenched disadvantage. Moreover, and moving beyond the rigid distinction often drawn between the biological and the social origins of disease, this paper reconceptualises disease as a bio-social phenomenon, produced in the dynamic relations of biological and social forces. In particular, it argues that the HIV epidemic in South Africa embodies poverty and therefore any attempt to address the epidemic must also address the mutually constituted problem of poverty. To put this slightly differently, the paper seeks to complicate a unidirectional model of disease causation in which poverty is understood to be a singular cause of diseases such as HIV/AIDS. According to this conventional understanding, poverty and disease are separate entities that impact on one another to generate predictable effects. The approach taken in this paper proposes instead a model of disease causation that is complex, relational and multi-linear by drawing attention to the reciprocal constitution of disease and poverty: in their recursive relations, poverty and $\mathrm{HIV}$ produce ontologies of disease that are unique to South Africa. Such an approach entails a different model of intervention, one that addresses the mutual constitution, and thus the ontological inseparability, of HIV and poverty in the South African context. In the analysis and concluding sections, I offer some suggestions for possible policy measures that operate on this alternative model of disease causation. They might include for example, the design of a treatment policy that aims not only to ensure the successful delivery of ART but also to redress the persistent social inequalities that shape the distribution, effects and, crucially, the materiality of HIV in South Africa.

\section{Theorising 'disease in the making'}

In order to make the argument that HIV/AIDS and poverty are co-constituted, I draw on a the work of science and technology studies scholar Annemarie Mol (2002) who 
argues that disease, like all phenomena, is always in the process of becoming. Mol calls her approach 'praxiography' to articulate its interest in the practices that make disease. Importantly, praxiography challenges both the natural scientific and social constructivist view of disease, arguing that both treat disease as a singular, stable object (either the product of nature or culture). Instead, praxiography theorises disease as an 'object-in-the-making' that is variously enacted in daily practices across different domains, such as hospitals, laboratories and public health policies. As Mol explains:

If we no longer presume 'disease' to be a universal object hidden under the body's skin, but make the praxiographic shift to studying bodies and diseases while they are being enacted in daily...practices, multiplication follows. In practice a disease $[\ldots]$ is no longer one. (2002, 83, emphasis original)

This refiguring of the ontology of disease as multiple and emergent has a number of significant implications. It enables an examination of the generative role of political, social and scientific practices in making disease - here practices are understood not as neutral mechanisms for intervening to 'address' disease but as directly shaping its very substance. Moreover, conceiving disease as ontologically multiple differs from what Mol calls perspectivalism, the claim that people have different perspectives on a unified object (Jensen and Winthereik 2005). A perspectivalist approach would likely argue that the Mbeki government and TAC viewed HIV/AIDS differently, but they were nonetheless apprehending the same, coherent object. That is, they had different perspectives on the same object. A praxiographic understanding eschews the idea that disease is a single, unified object and conceives it instead as a 'texture of partially coherent and partially coordinated enactments' (Jensen and Winthereik 2005, 266). 
This theoretical approach also departs from critical anthropological, biocultural and syndemics theories (see for example, Weaver and Mendenhall 2013, Singer 2009, Leatherman and Goodman 2011), which although they offer valuable insights into the political, social and cultural processes that shape disease, tend to treat these processes as separate from disease itself. On this view, disease has an underlying nature, or fixed biological substrate, on which social and cultural forces act to shape its effects across individuals and populations. By contrast the approach taken in this paper seeks to illuminate the performative role of political and social forces, notably poverty, in shaping the very materiality of the disease HIV/AIDS.

To theorise HIV/AIDS as a 'disease in the making', this paper additionally draws on feminist theorist Karen Barad's agential realist approach, which contributes to the emerging body of 'new materialist' ${ }^{2}$ scholarship that seeks to account for the agency of biology or matter in the making of realities. Responding to the discursive turn in recent post-structuralist scholarship and its tendency to treat materiality as reducible to discourse, Barad's agential realism offers a robust theorisation of the role of matter and discourse in the production of realities without treating either as determining. In other words, her approach provides a persuasive response to the problem of how to think matter and meaning together, avoiding the tendency either to neglect one of them or to instate a fixed ontological distinction between them.

To express the relationality of matter and discourse, Barad proposes the neologism intra-action. Where the more familiar term interaction refers to relations between separate, pre-existing entities (e.g. matter and discourse), intra-action signifies that discourse and matter emerge through each other within phenomena. Important to note 
here is Barad's use of the term 'phenomenon' to counter the traditional notion of the 'object' as an independently existing entity. For Barad, the phenomenon is 'produced through...[the] intra-actions of multiple material-discursive practices' and as such, it is constantly in the making $(2007,206)$. Because Barad's approach treats materiality as emergent, it enables me to theorise HIV/AIDS as both a socially constructed and thoroughly material phenomenon and to track the social forces that shape its materiality. Within a conventional realist model this materiality is ordinarily understood as developing 'naturally', and the substance of disease is taken to be the effect of a hypostatised biology. A key task of this paper is to denaturalise this understanding and rethink the ontological status of disease without installing it as either fixed and given in nature or the effect of social-cultural processes, which appear resistant to change.

Barad's notion of intra-activity dovetails with Mol's praxiography in that both concepts propose a relational ontology: they posit phenomena as produced in their relations rather than as ontologically separate, bounded entities. It is this shared interest in ontological 'relatedness' or entanglements that makes Barad's and Mol's approaches important for the concerns of this paper. Reading their insights through one another enables me to examine the ways in which HIV/AIDS and poverty in South Africa are ontologically entangled and to trace the intra-actions that produce this entanglement. This involves paying particular attention to the role of povertyand the associated problems of overcrowded informal housing arrangements, food insecurity and an overburdened public health system-in producing specific, sometimes damaging materialisations of HIV/AIDS in South Africa. 


\section{Methods}

In what follows, I analyse a selection of statements made by government elites and activist leaders on the relationship between HIV/AIDS and poverty. Of course, the statements made by political elites cannot be taken as representative of the many, different views circulating in government and civil society during the time of Mbeki's presidency. This caveat notwithstanding, it seems to me that the views of political elites warrant scrutiny, not least because they often have considerable influence on policy.

In selecting the materials for this analysis, I performed online searches of the website of the ruling party, the African National Congress (ANC), for documents published between 1999 and 2008 (coinciding with Mbeki's presidency), which were oriented to the theme of 'AIDS and poverty'. In order to examine TAC's account, I conducted a search of the only archival collection of TAC's political papers in existence. Titled 'The Zackie Achmat, Jack Lewis and Treatment Action Campaign Political Papers' (1971-2005), this collection is available at the South African History Archive. The keywords and phrases used to conduct the searches were: 'HIV/AIDS and poverty', 'disease of poverty', 'health and poverty', 'poverty alleviation', 'poor', 'impoverished/impoverishment'. The searches yielded eleven government documents and fifteen TAC documents which were reviewed, and those which provided insight into the relationship between HIV/AIDS and poverty were analysed in depth.

I begin the analysis by highlighting the cause-effect logic implicit in both the government and TAC's understandings of how AIDS and poverty are related, and I 
propose a rethinking of the disease-poverty relationship that disrupts classic causal logic.

\section{The dynamics of AIDS and poverty: a challenge to linear causal logic}

I came to the conclusion that as Africans we are confronted by a health crisis of enormous proportions. One of the consequences of this crisis is the deeply disturbing phenomenon of the collapse of immune systems among millions of our people, such that their bodies have no natural defense against attack by many viruses and bacteria [...] As I listened and heard the whole story told about our own country, it seemed to me that we could not blame everything on a single virus.

It seemed to me also that every living African, whether in good or ill health, is prey to many enemies of health that would interact one upon the other in many ways, within one human body. (Mbeki 2000b)

As is evident in his speech (quoted above) at the opening of the Thirteenth International HIV/AIDS conference in Durban South Africa, Mbeki did not dismiss HIV as among the causes of AIDS in Africa. Neither did he deny the scale of the epidemic, depicting it as a 'health crisis of enormous proportions' that 'confront[s] Africans' (2000b). However, he contested the prevailing scientific view that AIDS has a single, underlying viral cause, or, as he puts it, 'it seemed to me that we could not blame everything on a single virus' (2000b). He argued, instead, that AIDS, or what he refers to as 'the collapse of immune systems' is caused by a variety of social, environmental and biological forces, figured via the metaphor of 'enemies of health' 
(2000b). By depicting 'enemies of health' as forces that interact 'one upon the other' to produce illness, Mbeki's formulation posits the existence of discrete objects that impact independently on one another, generating predictable effects on the individual 'human body'. These effects include a collapsed immune system (or in biomedical terms, AIDS), which prevents the body from defending itself against viruses or bacteria and thus hinders its capacity to stave off illness. Here the disease AIDS is depicted as the predictable result of separate but interacting causal factors ("enemies of health'), which, according to Mbeki, include 'poor nutrition, unavailability of clean water, unhygienic environmental conditions, [and the] unaffordability of drugs' (2000a).

TAC presents a somewhat similar account of the connection between poverty and HIV, proposing poverty as both 'a cause and consequence of HIV-infection' (TAC Science and Research Committee 2001, 38). In doing so, it acknowledges the twoway traffic between HIV and poverty:

Poverty contributing directly to the epidemic:

Particular groups are vulnerable to the disease as a consequence of their living without adequate means [...] Poverty also indirectly contributes to this epidemic and other diseases by causing poor physical health of people as well as through people's reduced control over circumstances [...]

Poverty resulting from the epidemic:

Certain households face the prospect of poverty purely because they lose a breadwinner, need to care for sick family members, or have to take care of relatives from other households. There is therefore a specific need to address poverty that results from the disease itself (38-9). 
As noted above, TAC proposes a model of disease causation in which poverty is understood to be both a cause and effect of HIV: not only does poverty enhance vulnerability to HIV-infection, it is also a consequence of HIV insofar as illness or death from HIV pushes households into poverty. Where the account articulated by Mbeki implies a unidirectional conception of poverty as a cause of HIV, TAC's account suggests the relationship between poverty and HIV is bidirectional. On this view, poverty is both a cause and effect of HIV. Yet despite this difference in their understanding of HIV causation, both TAC and the government treat poverty and HIV/AIDS as separately determinate entities that interact with each other in linear ways to generate predictable effects. This view of the HIV/AIDS-poverty nexus is consistent with current thinking in the sociological, public health and medical anthropological literature on HIV/AIDS (see for example, Gillies, Tolley, and Wolstenholme 1996, Gillespie 2006, Loevinsohn and Gillespie 2003). However, HIV/AIDS and poverty can also be understood in more relational terms as imbricated or enfolded in each other such that they defy explanation using deterministic "cause and effect' logic. Exceeding both the unidirectional and bidirectional models of causation articulated above, we might productively understand the HIV-poverty dynamic as multi-directional, recursive and, perhaps most importantly, one in which HIV and poverty are ontologically entangled phenomena rather than separately determinate entities. Reconceived this way, and following a new materialist understanding of causation as complex and multi-linear (Frost 2011), disease emerges as a multiply co-constituted phenomenon (Rosengarten 2009), formed in its encounters (intra-actions) with poverty-related conditions such as poor nutrition, inadequate healthcare and access to clean water (themselves co-constituted phenomena). Conditions of poverty are understood, not as separate, 'environmental' 
factors that cause disease or exacerbate its effects, but as embedded in and inextricable from the substance of disease. In other words, I am proposing that disease embodies what is usually seen as its environment. This means that disease can be 'considered ontologically different when formed on different occasions' and in relation to different phenomena, including poverty (Rosengarten 2009, 63). The idea that disease is ontologically multiple follows Mol's (2002) praxiographic approach, outlined above. In Mol's words, disease is always already 'more than one and less than many' $(2002,5)$. It materialises in multiple ways but somehow coheres as an apparently unitary object. According to this conceptualisation, disease is both materially shaped by and helps to shape its environment so that when so-called environmental or social conditions change so too does the substance - the very materiality—of disease.

To elaborate on this reconceptualisation and explore its implications for HIV/AIDS in South Africa, it is necessary to examine more closely the government and TAC's understandings of the relationship between HIV/AIDS and poverty. In conducting this enquiry, I analyse the government's argument that virological explanations for AIDS medicalise poverty, demonstrating its role in dividing disease into two apparently distinct domains, namely the biomedical and the social. My analysis draws attention to the significance of this division for the making of HIV/AIDS in South Africa.

\section{HIV/AIDS and the 'medicalisation of poverty'}

In examining the Mbeki government's critique of what it terms the 'medicalisation of diseases of poverty', I refer to an essay on HIV/AIDS, which was circulated in the 
ANC ruling structures during Mbeki's term of office. Entitled 'HIV/AIDS and the Struggle for the Humanisation of the African', the 114-page essay is believed to have been written by the then chief electoral officer of the ANC Peter Mokaba with assistance from Mbeki although Mbeki did not openly endorse the essay (Shisana and Simbayi 2002). In Chapter III, the authors lament what they see as the inadequacies of a medicalised approach to addressing 'Africa's health challenges':

[T]he omnipotent apparatus disapproves of our effort seriously to deal with the serious challenge in our country of health, poverty and underdevelopment $[\ldots]$ According to this argument, necessarily, therefore, the two principal and decisive responses open to us, to respond to Africa's health challenges, are the use of condoms and the consumption of anti-retroyiral drugs. Everything else that causes ill health and death among us, the omnipotent apparatus argues, is of peripheral importance. (Anonymous 2002, Chapter III)

A couple of issues are collapsed in this passage that would benefit from being teased out. The authors critique the two central planks of the dominant biomedical response to HIV: 1) behavioural change measures, notably the promotion of condom use to prevent HIV transmission, and 2) anti-retroviral drugs, which are currently the most effective form of HIV-treatment. They argue that by prioritising the use of condoms and anti-retroviral drugs as the 'principal [...] responses [...] to Africa's health challenges', the international AIDS orthodoxy (or to use the authors' rather more conspiratorial terms, 'the omnipotent apparatus') is annexing broader problems of poverty and underdevelopment in Africa under the biomedical umbrella of HIV/AIDS.

Later, in chapter XII the authors revisit this theme: 
[O]ne purpose they [Africans] serve for those who fatten them, is to medicalise poverty and underdevelopment. Thus problems that require a determined global effort to end African poverty and underdevelopment are presented, with African acquiescence, as problems that can be solved with condoms and drugs. (Chapter XII)

Both extracts contest the promotion of behavioural and biomedical measures ('condoms and drugs') for managing HIV/AIDS on the basis that they medicalise the problem of poverty, which the Mbeki government claimed was the underlying cause of 'Africa's health challenges', including AIDS (Chapter III). The term 'medicalise' would benefit from a brief definition at this point. To medicalise something is to place it under the aegis of medicine and therefore understand it as responsive to medical intervention. The term first emerged in the 1970 s in the social scientific literature and has generally been used to critique the increasing power of medicine in preventing and treating disease, managing 'health risks' and optimising human life (Conrad 1992, Persson 2013). Sociologist Deborah Lupton notes that, according to proponents of the medicalisation critique, the 'increasing power of scientific medicine [...] has detrimental effects for traditionally disempowered and exploited social groups by deflecting questions of social inequality into the realm of illness and disease, there to be treated inappropriately by drugs and other medical therapies' $(1997,96)$.

In critiquing the medicalisation of poverty and underdevelopment in Africa, Mbeki and his supporters draw on political philosopher Herbert Marcuse's notion of the 'omnipotent apparatus' to describe powerful social structures that demand conformity (Marcuse 1970 cited in Anonymous 2002, Chapter I). In this account, the omnipotent apparatus seems to denote not an abstract set of social structures but a concrete object 
of criticism, namely the international AIDS orthodoxy or what Youdé $(2007,18)$ refers to as the 'international AIDS control regime', an epistemic community of Western scientists, public health practitioners, multinational pharmaceuticals, policymakers, HIV/AIDS organisations and activists. According to the authors of this document, the power of the omnipotent apparatus resides in its use of insidious disciplinary mechanisms that sustain 'repression from within' (Chapter I). These mechanisms relate to what Marcuse calls 'introjected heteronomy' in which the oppressed internalise and reproduce the ideas of their oppressors, effectively sustaining their own subordination (Marcuse 1970 cited in Anonymous 2002, Chapter I). The government's medicalisation critique is therefore directed not only at the powerful international AIDS orthodoxy but also at those perceived to be oppressed by this orthodoxy, namely African scientists and academics. Implicit throughout the AIDS dissident document quoted here is the suggestion that these African scholars uncritically accept Western science's explanation of the HIV epidemic in Africa and in so doing, sustain Africa's subordination to Western regimes of knowledge and power. This is evident in the above quote when the authors note that 'problems that require a determined global effort to end African poverty and underdevelopment are presented, with African acquiescence, as problems that can be solved with condoms and drugs (Anonymous 2002, Chapter XII, emphasis added).

By claiming that the international AIDS establishment ('the omnipotent apparatus') medicalises diseases of poverty in Africa, the government resists what it sees as misguided attempts to place the problem of poverty within the province of medicine to be solved through biomedical treatments. Essentially, the Mbeki government's medicalisation critique presents an argument against an exclusively or predominantly biomedical/technoscientific response to HIV/AIDS on the basis that it does not 
adequately address the disease's social causes and is driven only by sinister profiteering (an attempt to 'fatten Africans'). However, by implicitly casting the social as distinct from and counter to the biomedical, the medicalisation critique retains the traditional dualism (and its implicit hierarchy) of biomedical/social knowledge. While recognising that this dualistic framing helped the government to advance their AIDS dissident position and their emphasis on addressing poverty and underdevelopment as key causes of disease, it also displaced from view more moderate understandings of disease causation that may have been expressed outside the polarised rhetoric of the debate. Importantly, the government's reliance on this dualism and, its associated attempt in accounts such as this to quarantine the social domains of HIV from medical ones, is not merely an epistemological issue; it generated some real and damaging effects. For one, by treating the cause of HIV as largely reducible to poverty and contesting the accepted medical explanation, the government sidelined existing biomedical technologies to treat those already infected and focussed instead on social and behavioural responses such as poverty alleviation strategies and behavioural change campaigns. Partly because of its expressed concerns about the toxicity of ARV drugs, the Mbeki government refused to deliver ART - the best available medical treatment for HIV/AIDS — as part of its approach to addressing the epidemic in South Africa. Only in late 2003, when a court decision compelled it to do so, did the Health Ministry under Mbeki implement a national ART programme (Low et al. 2010).

The distinction drawn between biomedical and social knowledge about disease is common, but as the South African case reveals, it is not only conceptually shaky but also materially harmful. In the case of HIV, the stakes are very high: during the period of Mbeki's presidency, an estimated 300000 people, reliant on public healthcare, died 
from treatable AIDS-related illnesses (Chigwedere et al. 2008). In Barad's agential realist terms, we can understand these deaths as produced through the intra-actions of HIV, the state of South Africa's public healthcare system, the government's reliance upon a medical/social dualism, an AIDS dissident policy, antagonistic relations between the state and local AIDS organisations, delays in delivering ART and other so-called political forces usually seen as separate from, if not irrelevant to, AIDSrelated mortality. Moreover, the government's reliance on a biomedical/social dualism arguably deflected attention away from other important intra-actions shaping HIV/AIDS in South Africa such as regional politicking and Mbeki's neoliberal economic policy which was inconsistent with his professed concern to alleviate poverty (Decoteau 2013).

In making this argument, I am not suggesting, following a linear causal logic, that any of these phenomena can be singled out as' a separately determinate 'cause' of AIDSrelated deaths (the 'effect'). Rather my point is that these phenomena and the deaths emerge in relation to each other. They make (and, sometimes, change) each other in their intra-actions and are therefore ontologically entangled. The AIDS deaths, for example, arguably helped to entrench the antagonistic relations between the South African government and local AIDS organisations, thus impeding action on HIV treatment and enabling more deaths from AIDS. The deaths are also likely to have confirmed the inadequacies of the public health system and Mbeki's HIV policy, deepening the public's lack of confidence in the already struggling public health sector (Harris et al. 2011) and quite possibly discouraging HIV-positive people from seeking care. In short, the high AIDS mortality rate under Mbeki is both materially shaped by and shapes these key political phenomena. 
By pointing out some of the limitations of the government's focus on so-called social strategies to combat AIDS (poverty alleviation and behavioural change measures), I am not suggesting that an exclusively biomedical response is the answer either. In order to gauge the effects of a predominantly medical approach, it is helpful to examine next TAC's approach to addressing HIV/AIDS in South Africa.

\section{Entangled ontologies: poverty in the making of HIV/AIDS}

Against the perceived threat posed by the government's AIDS dissidence, TAC supported the biomedical model of AIDS causation, arguing that 'Only HIV predicts AIDS [...] No other factor on its own, including drug use, diet or poverty, is sufficient to cause AIDS' (Geffen 2006, 2). As this statement implies, TAC members understood poverty as a distal factor that contributes to AIDS but not its primary causal agent. Coupling a biomedical account with a pro-poor treatment movement, TAC focussed on one aspect of poverty as crucial to combatting AIDS, namely access to healthcare.

Nathan Geffen, former TAC treasurer, explains the connection between poverty and AIDS in the following terms, pointing out what he sees as an important oversight in Mbeki's formulation:

There is one particularly crucial way in which poverty exacerbates Aids [sic] that Mbeki almost entirely ignored [...] Poor people do not have access to the health services of the well-off [...] Until ARVs and other medicines for opportunistic infections were widely available in the public health systemand even since - the poor died of Aids [sic] in large numbers in South Africa 
precisely because it was much more difficult for them than for well-off people with medical insurance to get ARVs. (2010, 28-9)

This statement frames the connection between poverty and AIDS in terms of access to affordable medical treatment, sidelining the role of other poverty-related forces in shaping vulnerability to HIV/AIDS, such as unemployment, food insecurity, poor sanitation facilities, makeshift housing conditions, and malnutrition. In so doing, it elevates the importance of biomedical measures (drugs) in addressing HIV and reduces the significance of other measures. Of course, such a response is understandable given the insufficiency of the government's approach, particularly its refusal to deliver ART. It is also worth emphasising that, once HIV-treatment became available in South Africa's public health system, TAC shifted their focus from treatment access to treatment literacy programs, which address the role of nutrition, access to safe drinking water and other poverty-related factors in managing HIV/AIDS (Peacock, Budaza, and Greig 2008). This suggests that TAC is cognisant of the multiple factors that shape the relations of poverty and HIV in South Africa, but this more nuanced understanding of the poverty-HIV dynamic drops out of view in the above account, which emphasises instead the absence of medical treatment in aggravating poverty and AIDS. With this in mind, it seems that the explanatory narrowness of the conception articulated here was at least in part an effect of the polarised HIV debate and the manifest inadequacies of the Mbeki government's HIV policy approach.

Intriguing, though, is Geffen's qualification that, even since ARVs have been publicly available, the poor have continued to die from AIDS. ${ }^{3}$ If access to ARVs, is the 
definitive factor governing the continued association of AIDS with poverty in South Africa, then why has access not resulted in a decoupling of poverty and death from AIDS? Perhaps the answer can be found in a rethinking of the relations of poverty, AIDS and ARVs. Geffen's statement seems to presume that poverty, AIDS and drugs are separate, autonomous entities that impact on each other in predictable ways. But they can also be understood as co-constitutive phenomena, made and transformed in their intra-actions. This different conception of the poverty-disease-drugs dynamic entails a rethinking of intervention. Instead of thinking of poverty and HIV/AIDS as subject to intervention and ARVs as the tool of intervention, it is useful to consider how poverty and HIV/AIDS are already an effect of intervention (Rosengarten 2009). Doing so might encourage the design of more adaptable, less one-dimensional treatment measures, ones that engage their own role (as part of a larger relational field) in making and changing the disease. The pursuit of such reflexive measures has the potential to prevent those working in the field of HIV/AIDS from proceeding as though they are merely responding to the disease - as if it were a transparently given object that precedes attempts to treat it using biotechnologies such as ARVs. It could open up possibilities for intra-acting with HIV as an agentive phenomenon that is changed by, and helps to change, particular treatment measures and technologies themselves. In concluding this paper, I consider what this rethinking of the povertyHIV dynamic might involve in terms of practical measures for addressing HIV/AIDS and the co-constituted problem of poverty.

In terms of the place of ARVs in this rethinking, I am not discounting the work of ARVs in treating HIV but rather arguing that ARVs do not act in a direct, linear way on the virus as their presumed target. Instead, they help to constitute the virus, just as 
ARVs themselves are constituted in their encounters with the virus. In other words, and following Rosengarten and Michael (2009), we can say that HIV and ARV drugs actively (and multiply) produce each other and therefore cannot be considered singular, bounded entities that merely interact in predictable ways. For example, in their encounters with HIV and with social practices of drug consumption and adherence, ARVs help to create drug-resistant strains of HIV, thus re-forming the virus. In the process, ARVs too are transformed, rendered less effective or even ineffective in combating the new drug-resistant forms of the virus. As more drugresistant forms of HIV emerge, the range of available treatment combinations is reduced, making HIV more difficult to treat, and in turn requiring new drugs.

This rethinking is also about recognising the role of multiple phenomena in shaping the ways in which HIV/AIDS and poverty are connected. I suggest that the continued deaths of poor people from AIDS, even in the presence of treatment, invites consideration of the larger relational field that helps to (re)produce poverty's association with AIDS in South Africa. In order to explore what this field might look like, I turn to Geffen's illustration of the link between AIDS and poverty, explained in terms of the situation of an HIV-positive man living in a township in Cape Town:

[HIV-positive] Andile Madondile took me to his tiny shack in Khayelitsha [a large township in Cape Town] which he shares with his wife and two children [...] There is no tap in Andile's shack. The one a few metres from it was vandalised by tsotsis [gangsters] and Andile's ward councillor has not done anything to repair it despite promising to do so. So the nearest tap is about 100 metres from his shack. The nearest toilet is even further. His shack, the tap and toilet make a triangle of inconvenient town-planning with devastating public 
health consequences. How is poverty related to Aids? [sic] For one thing, as Andile's circumstances show, it makes day-to-day living with the virus and opportunistic infections difficult. Diarrhoea is a part of life in the advanced stages of HIV. $(2010,27)$

According to Geffen, Andile's situation demonstrates a causal chain between circumstances of poverty and AIDS-related illness: the location of sanitation and clean drinking water far from Andile's shack cause 'devastating public health consequences' including AIDS-related illnesses, such as diarrhoea (27). Poverty is also seen as exacerbating the effects of these illnesses by 'making day-to-day living with [...] opportunistic infections difficult' (27). On this reading, it is possible to infer that, all other things being equal, if Andile were living in more affluent conditions, he might not experience AIDS-related illness or at least, it would not be as debilitating. Of the factors that could be said to cause Andile's illness, Geffen singles out the location of his shack in relation to the tap and toilet, describing it as a 'triangle of inconvenient town-planning' (27).

However, Andile's illness can also be seen as emerging in relation to a complex assemblage of phenomena that include, but are not limited to, the location of his shack. Some of these phenomena are mentioned in the extract above, and some can be inferred from the fuller account of Andile's story told earlier in Geffen's book. They include HIV, unemployment, malnutrition, the decision not to take ARVs, dense informal housing, the effects of vandalism in the township, poor municipal management and the location of flush toilets and clean water. In their intra-actions, these phenomena constitute Andile's AIDS-related illness and are themselves 
reconstituted. The dynamic process of intra-activity complicates assumptions about a neat causal relationship between the apparently discrete entities of AIDS and poverty. It illuminates Andile's illness as embodying (rather than simply caused by) povertyrelated phenomena. So the diarrhoea Andile experiences can be understood not simply as the product of an AIDS-related opportunistic infection (although the infection and Andile's HIV status are important factors) but also as a product of the phenomenon of poverty. Thus, it is possible to see AIDS as a qualitatively different disease when it is materialised in poor, under-resourced settings than when it is materialised in comparatively affluent, well-resourced ones. This is not to suggest that poverty merely contributes to hastening the onset of AIDS or that it exacerbates its symptoms but rather that it is integral to the ontology of the disease in South Africa. So for example, in its encounters with limited sanitation facilities, dense living conditions, unemployment, malnutrition and other poverty-related phenomena, HIV/AIDS materialises through preventable opportunistic infections such as diarrhoea. Although these infections are easily treated and not usually the source of prolonged illness, in cases such as Andile's, they materialise as severe, debilitating and potentially life-threatening illnesses. By extension, in poverty-stricken settings where ART is not available, the association between HIV and AIDS is reproduced. In the process, poverty itself is cemented, and the poverty-disease nexus is further reified: because of his illness, Andile is unlikely to be able to seek employment that would enable him to access the financial and medical resources necessary to regain his health and improve his socioeconomic circumstances. In other words, in cases such as Andile's, HIV embodies and helps to reproduce poverty in South Africa. By contrast, in well-resourced settings, the availability of ART has enabled HIV and AIDS to be decoupled, challenging the assumption of an ineluctable progression from 
HIV to AIDS. The key point here is that the materiality of HIV/AIDS (including its presumed 'progression') is not given in nature and immutable. Rather, it is socially constituted, emerging through social forces and processes, including those associated with poverty. To put this slightly differently, disease cannot be separated from its relational context; it is formed and reformed through it. In the context of South Africa, poverty, racial inequalities and other so-called structural phenomena can no longer be regarded as ontologically distinct entities; rather they are part of the politics that makes disease and that contributes to variations in its distribution and effects.

\section{Conclusion}

This paper has examined two conceptions of the relationship between HIV/AIDS and poverty, both of which, despite their differences, rely on the biological/social dualism: disease as either biological or social in origin. TAC endorsed the biological (or biomedical) account of HIV/AIDS arguing that while poverty contributes to the disease, HIV is an infection, and its causes are viral. It cited lack of access to healthcare as the reason for the concentration of the South African epidemic amongst the poor. By contrast, Mbeki and his supporters maintained that AIDS is most properly understood as social in origin, arguing that AIDS is a symptom of endemic poverty in South Africa. In comparing these two accounts of the relationship between HIV/AIDS and poverty, this paper has revealed how, as an effect of the apparent polarisation of the debate, they tended to be treated as mutually exclusive. It is likely that beyond the confines of a polarised debate and outside their most heated speeches, both the Mbeki government and TAC would advance a more nuanced, relational conception of HIV causation that recognises the role of both biological and social forces in shaping the disease, its distribution and effects. In other words, I suggest that 
their views actually share more in common than existing popular and scholarly accounts allow (see for example, Butler 2005, Wang 2004, Nicholson 2014, Geffen, Venter, and Conradie 2012). Extending this point, it is possible to argue that the polarised debate belied any shared ground in TAC and the government's approaches to HIV and prevented each party from conceding the legitimacy of the other's position. Furthermore, both accounts - in their intra-actions with each other and with the presumption of a polarised debate - actually did little to combat HIV as they held South Africa in aspic as it were, paralysing the national response and impeding action on the epidemic, perhaps most importantly by preventing the delivery of life-saving treatment.

Against the debate's dualistic framing of biological and social models of disease causation, I have queried the assumption that the medical and the social are ontologically distinct categories and posited disease as a medico-social phenomenon. Indeed the biological/social binary at the heart of these conceptions proves inadequate in the face of the disease's complexity: AIDS cannot be understood only as a syndrome caused by a virus (a biological object), nor merely as a symptom of social factors such as poverty, which appear resistant to change. By holding fast to the biological/social dualism and thus reiterating the enduring ontological distinction it presumes, these conceptions of disease preclude, or at least limit, the possibility of understanding HIV/AIDS as thoroughly biological and social, its materiality forged through the inextricable entanglements of biological and social forces. Within a conventional realist model, this materiality is ordinarily understood as developing 'naturally', and the substance of disease is taken to be the effect of a hypostatised biology. The new materialist approach I am elaborating seeks to denaturalise this 
understanding and rethink the ontological status of disease without installing it as either fixed and given in nature or the effect of social-cultural processes, which appear resistant to change. As previously noted, the conception of disease causation proposed here is also different to the syndemics theories developed in critical medical anthropology that seek to bridge biocultural methods and concepts by tracing connections between biological and social causes that contribute to disease epidemics. As Weaver and Mendenhall explain, syndemics theories illuminate 'the interaction of social, psychological, and biological factors that contribute to illnesses across cultures and across time'(2013, 93). While offering a valuable synthesis of biocultural and critical anthropological conceptions of disease, syndemics approaches nonetheless tend to treat social, cultural, psychological and biological factors as distinct. That is, these factors are seen as interacting to influence patterns of vulnerability to disease, but ultimately each factor still retains its separate existence, allowing its effects to be distinguished from other 'contextual' factors and from disease itself. By contrast, the relational conception I am proposing recognises the ontological inseparability of the biological and the social (and relatedly nature and culture) in producing disease. Or as Barad (2011) might put it in the terms of quantum physics, it conceives disease as a phenomenon composed of the quantum entanglements of biological, social, natural and cultural forces. On this rethinking, these forces and disease produce each other, even as each undergoes change.

Effective, nuanced HIV interventions depend on the ability to understand the biological dimensions of the disease (its presumed underlying nature) as inextricably entangled with the social, cultural and political realities through which it is materialised. Observing the social constructedness of disease is not to imply that disease has no biological reality. Neither is it to deny the real and damaging effects of 
disease. Rather, it is to draw attention to the (often overlooked) role of social forces in shaping the ontology of disease and its effects. As Singer puts it, in defending what she calls the social origins of disease: 'This is not a denial of the material reality of biology, nor of the real effects of pathogenic agents and other disease causing entities. How we think about their health effects, how we group and label them, the meanings we invest in them, how we act on this construction (i.e. the making of disease) is not specified in biology. It is a cultural process' (Singer 2004, 13, original emphasis).

The approach to disease described here invites the recognition that, in the context of South Africa, HIV/AIDS both embodies and helps to (re)produce poverty. I am proposing, in other words, an approach that attends to the ways in which HIV/AIDS and poverty intra-act to produce ontologies of the disease that are unique to South Africa. This might involve, for example, the design of a treatment policy that aims not only to ensure the successful delivery of ART but also to redress the persistent social inequalities that shape the distribution, effects and, indeed, the materiality of HIV in South Africa. It could include provisions for some or all of the following:

- monitoring and addressing mismanagement in the public health system (Amado et al. 2012b);

- state-subsidised formal housing;

- a universal basic income grant; and

- improving delivery of basic municipal services and infrastructure (Roux and Nyamukachi 2005), particularly in informal housing settlements and rural areas.

It is encouraging to note that some policies and initiatives are already in place to address some of these issues. Perhaps most significantly South Africa's current 
National Strategic Plan for HIV includes a set of goals addressing the structural barriers to HIV prevention, care and treatment (Department of Health 2012). One of these goals directly addresses the poverty-disease nexus by aiming to strengthen poverty reduction and food security programs. However, despite the NSP's laudable aim of addressing the poverty-HIV dynamic, it is noteworthy that the emphasis is very much on testing and treatment with $85 \%$ of the total budget allocated to these programs (Amado et al. 2012a). In terms of the provision of public housing subsidies, the ANC government introduced housing subsidies for low-income households as part of its Reconstruction and Development Program (RDP), and by 2009, 75\% of South African households were living in formal housing (Shapurjee and Charlton 2013). Notwithstanding the massive investment in housing and the delivery of almost three million houses since 1994, informal housing persists in some areas (Shapurjee and Charlton 2013). In relation to the provision of universal basic income support, two South African activist groups, the Khayelitsha Progressive Youth Movement and the New Women's Movement, have held protests demanding a basic income grant (Shapurjee and Charlton 2013). Yet despite the backing of many civil society organisations and broad popular support (Harris et al. 2011), the South African government has yet to propose basic income support measures. Finally, poor municipal service delivery is a persistent challenge facing the South African government, and service delivery protests and related efforts to improve the delivery basic municipal services are ongoing (Amado et al. 2012b).

As mentioned, it is heartening to see that some measures are already in place to address the HIV-poverty nexus in South Africa but many challenges remain, not least the lack of basic income support for vulnerable households and mismanagement in 
the public health system that undermines the reliable provision of ART (Bateman 2013). In light of these ongoing challenges and the enduring association of HIV/AIDS and poverty, the policy suggestions above are worth considering. Moreover, while I acknowledge the challenge of affording all the measures proposed here, it is important to stress that pursuing even just one or two of them would change other domains too. If we understand objects as multiply co-constituted phenomena, whatever investments are made on one phenomenon (here HIV/AIDS) will extend to others. That is, the effects of particular responses to disease would be more far-reaching than one can anticipate because HIV/AIDS is, as we have seen, always already entangled with other social problems such as poverty, unemployment, material disadvantage and an uneven distribution of healthcare. It is this insight that separates the measures I am suggesting from those that others, working within a conventional realist approach, have suggested.

Effective disease interventions also depend on a willingness to move beyond the prevailing view of disease as a singular, stable object and understand it instead as 'more than one and less than many' — as multiple, materially different enactments that somehow hold together (Mol 2002, 5). As Mol's work amply demonstrates, disease is not a pre-formed, fixed object that precedes human action; it is a labile phenomenon, continually made and remade in human action. The praxiographic approach that Mol elaborates allows an account of disease that addresses its ontological multiplicity by illuminating the various enactments of disease produced in the intra-actions of political, social, and biological forces. It is the multiplicity and open-endedness of disease, I suggest, that holds both the promise and the challenge of developing 
dynamic and therefore, more effective measures for addressing diseases like HIV/AIDS.

\section{Endnotes}

${ }^{1}$ The Human Immunodeficiency Virus (HIV) is the virus that causes Acquired Immune Deficiency Syndrome (AIDS) (Centers for Disease Control and Prevention (CDC) 2006). AIDS is a cluster of diseases and opportunistic infections that break down the body's immune defenses. Following the medical distinction drawn between HIV and AIDS, I use 'AIDS' to refer to the late stage of HIV infection where the immune system is severely compromised, as indicated by a low white blood cell count and/or by the presence of AIDS-related opportunistic infections such as tuberculosis, diarrhoea and pneumonia. The term 'HIV' is used to denote the virus that helps to produce AIDS. In all other cases, I use the term 'HIV/AIDS' to refer jointly to the virus and the syndrome, that is, to the disease, more generally. This last usage is intended to capture the enduring association between HIV and AIDS in contexts where, for example, anti-retroviral treatment (ART) is not available and/or where poverty and other phenomena prevent a decoupling of the two.

${ }^{2}$ Consistent with the 'ontological' turn in contemporary social theory, new materialist approaches challenge the notion that matter is inert and passive, emphasising the agency of matter in the creation and transformation of phenomena (Lezaun 2014, Dolphijn and van der Tuin 2012). They also conceive of the process of materialisation as ongoing, complex and contingent on social and political forces. According to this view, social actors and theorists actively help to make realities and therefore the practices and concepts they employ have performative power: they bring certain realities into being and foreclose the existence of others.

${ }^{3}$ Although no official data are available on HIV mortality by income group in South Africa, the current National Strategic Plan (NSP 2012-2016) notes that poverty is a major contributor to HIV in South Africa and identifies people of low socio-economic status as a key population for targeted interventions because of their increased risk of contracting HIV (Department of Health 2012). Furthermore, the NSP recognises the high mortality rate associated with tuberculosis and HIV co-infection, which itself is 
closely connected to poverty in South Africa (Department of Health 2012). Read together, these observations, which are based on national epidemiological data, would seem to support Geffen's claim that many poor people continue to from AIDS in South Africa, even in the post-treatment era. 


\section{References}

Amado, Leandra Anastasia, Nicholas Christofides, Raymond Pieters, and Jody Rusch. 2012a. National Health Insurance: A Lofty Ideal in need of Cautious, Planned Implementation. Vol. 5. National Health Insurance; Universal Healthcare; Resource Allocation.

.... 2012b. "National Health Insurance: A Lofty Ideal in need of Cautious, Planned Implementation." South African Journal of Bioethics and Law 5 (1):4-10.

Anonymous. 2002. "Castro Hlongwane, caravans, cats, geese, foot and mouth and statistics: HIV/AIDS and the Struggle for the Humanisation of the African." Accessed 12 August 2010. http://www.virusmyth.com/aids/hiv/ancdoc.htm?

Barad, Karen. 2007. Meeting the Universe Halfway: Quantum Physics and the Entanglement of Matter and Meaning. Durham: Duke University Press.

..... 2011. "Nature's Queer Performativity." Qui Parle 19 (2):121-158.

Bateman, Chris. 2013. "Drug Stock-outs: Inept Supply-chain Management and Corruption." SAMJ: South African Medical Journal 103:600-602.

Butler, Anthony. 2005. "South Africa's HIV/AIDS Policy, 1994-2004: How Can it be Explained?" African Affairs 105 (417):591-614.

Centers for Disease Control and Prevention (CDC). 2006. "HIV/AIDS Basics." Accessed 23 January 2013 http://www.cdc.gov/hiv/resources/qa/definitions.htm

Chigwedere, Pride, George Seage, Sofia Gruskin, Lee Tun-Hou, and M Essex. 2008. "Estimating the Lost Benefits of Antriretroviral Drug use in South Africa." Journal of Acquired Immune Deficiency Syndrome 2008:1-6.

Conrad, Peter. 1992. "Medicalization and Social Control." Annual Review of Sociology 18:209-232.

Decoteau, Claire. 2013. Ancestors and Antiretrovirals: The Biopolitics of HIV/AIDS in South Africa. Chicago: University of Chicago Press.

Department of Health. 2012. The National Strategic Plan on HIV, STIs and TB (2012-2016). Accessed 31 July 2014. http://www.hst.org.za/sites/default/files/hiv_nsp.pdf

Dolphijn, Rick, and Iris van der Tuin. 2012. New Materialism: Interviews and Cartographies. Ann Arbor: Open Humanities Press.

Geffen, Nathan. 2006. "How we know that HIV causes AIDS." Equal Treatment: Newsletter of the Treatment Action Campaign March 2006 (19). Accessed 18 March 2011. www.tac.org.za 
2010. Debunking Delusions: The Inside Story of the Treatment Action

Campaign. Johannesburg: Jacana Media.

Geffen, Nathan, Francois Venter, and Francesca Conradie. 2012. "Helen Epstein's wrong about SA's response to AIDS." Politics web. Accessed 1 August 2012. http://www.politicsweb.co.za/news-and-analysis/helen-epsteins-wrong-aboutsas-response-to-aids

Gillespie, Stuart. 2006. AIDS, poverty, and hunger: Challenges and Responses, Highlights of the International Conference on HIV/AIDS and Food and Nutrition Security, Durban South Africa, April 14-16, 2005. Washington, DC: International Food Policy Research Institute.

Gillies, P., K. Tolley, and J. Wolstenholme. 1996. "Is AIDS a Disease of Poverty?" AIDS Care 8 (3):351-364. doi: 10.1080/09540129650125768.

Harris, Bronwyn, Jane Goudge, John E. Ataguba, Diane McIntyre, Nonhlanhla Nxumalo, Siyabonga Jikwana, and Matthew Chersich. 2011. "Inequities in Access to Health Care in South Africa." Journal of Public Health Policy 32 (S1):102-123.

Jensen, Torben Elgaard, and Brit Ross Winthereik. 2005. "Review of The Body Multiple: Ontology in Medical Practice." Acta Sociologica 48 (3):266-268.

Leatherman, Tom, and Alan H. Goodman. 2011. "Critical Biocultural Approaches in Medical Anthropology." In A Companion to Medical Anthropology, edited by Merrill Singer and Pamela I. Erickson, 29-48. Malden, MA: Wiley-Blackwell.

Lezaun, Javier. 2014. "A Reader's Guide to the 'ontological turn' - Part 2."

Somatosphere. Accessed 14 February 2014.

http://somatosphere.net/2014/01/a-readers-guide-to-the-ontological-turn-part2.html

Loevinsohn, Michael, and Stuart R Gillespie. 2003. HIV/AIDS, food security and rural livelihoods: Understanding and Responding. IFPRI: Washington, DC.

Low, Marcus, Catherine Tomlinson, Mara Kardas-Nelson, Kay Kim, and Nathan Geffen. 2010. Fighting for our Lives: the History of the Treatment Action Campaign (1998-2010). Cape Town: Treatment Action Campaign.

Lupton, Deborah 1997. "Foucault and the Medicalisation Critique." In Foucault, Health and Medicine edited by Alan Peterson and Robin Bunton, 94-112. London: Routledge.

Mbeki, Thabo. 2000a. "Health, Human Dignity, and Partners for Poverty Reduction." ANC Today 2 (14). Accessed 4 April 2011. http://www.anc.org.za/docs/anctoday/2002/at14.htm 
2000b. Speech of the President of South Africa, Thabo Mbeki, at the opening session of the 13th International AIDS Conference. Accessed 31 January 2013. http://www.virusmyth.com/aids/news/durbspmbeki.htm

McNeil, Jodi. n.d. "A History of Official Government HIV/AIDS Policy in South Africa." South African History Online. Accessed 27 July 2014. http://www.sahistory.org.za/topic/history-official-government-hivaids-policysouth-africa

Mol, Annemarie. 2002. The Body Multiple: Ontology in Medical Practice. Durham/London: Duke University Press.

Nicholson, Greg. 2014. "TAC: Funding, Accountability and the dire Consequences of Closure." Daily Maverick. Accessed 3 October 2014. http://www.dailymaverick.co.za/article/2014-10-03-tac-fundingaccountability-and-the-dire-consequences-of-closure/\#.VdaEQPmqpBc

Peacock, Dean, Thokozile Budaza, and Alan Greig. 2008. "The Treatment Action Campaign's activism." In HIV/AIDS and Society in South Africa, edited by Angela Ndinga-Muvumba and Robyn Pharaoh, 85-102. Scottsville: University of KwaZulu-Natal Press.

Persson, Asha. 2013. "Non/infectious Corporealities: Tensions in the Biomedical Era of 'HIV normalisation'." Sociology of Health \& Illness 35 (7):1065-1079. doi: 10.1111/1467-9566.12023.

Rosengarten, Marsha. 2009. HIV Interventions: Biomedicine and the Traffic between Information and Flesh. Seattle: University of Washington Press.

Rosengarten, Marsha, and Mike Michael. 2009. "Rethinking the Bioethical Enactment of Medically Drugged Bodies: Paradoxes of Using Anti-HIV Drug Therapy as Technology for Prevention." Science as Culture 18 (2):183-199.

Roux, Nico L, and PM Nyamukachi. 2005. "A Reform Model for the Improvement of Municipal Service Delivery in South Africa." Journal of Public Administration: Special Issue 3 40:687-705.

Schneider, Helen. 2002. "On the Fault-Line: The Politics of AIDS Policy in Contemporary South Africa." African Studies 21 (1):145-167.

Shapurjee, Yasmin, and Sarah Charlton. 2013. "Transforming South Africa's lowincome Housing Projects through Backyard Dwellings: Intersections with Households and the State in Alexandra, Johannesburg." Journal of Housing and the Built Environment 28 (4):653-666.

Shisana, Olive, and Leickness Simbayi. 2002. Nelson Mandela HSRC Study of HIV/AIDS: South African National HIV Prevalence, Behavioural Risks and Mass Media Household Survey. Accessed 26 July 2012. http://www.wsu.ac.za/hsrc/html/2007-2.pdf 
Simelela, NP, and WDF Venter. 2014. "A brief History of South Africa's Response to AIDS." SAMJ: South African Medical Journal 104 (3):249-251.

Singer, M. 2009. Introduction to Syndemics: A Critical Systems Approach to Public and Community Health. Malden, MA: Wiley.

Singer, Merrill. 2004. "The Social Origins and Expressions of Illness." British Medical Bulletin 69 (1):9-16. doi: 10.1093/bmb/ldh016.

TAC Science and Research Committee. 2001. Draft discussion document: Integrated framework for a national HIV/AIDS treatment and prevention plan. In The Zackie Achmat, Jack Lewis and Treatment Action Campaign Political Papers. Johannesburg: South African History Archive (SAHA), University of the Witwatersrand.

Tshabalala-Msimang, Manto. 1999. Statement to the National Assembly by Dr. ME Tshabalala-Msimang MP, Minister of Health, on HIV/AIDS and Related Issues. Debates of the National Assembly (16 November 1999). Accessed 23 May 2013. http://www.info.gov.za/speeches/1999/0001131124a1002.htm

UNAIDS. 2012. "HIV and AIDS Estimates." Accessed 11 December 2013. http://www.unaids.org/en/regionscountries/countries/southafrica/

Wang, Joy. 2004. "AIDS Denialism and 'The Humanisation of the African'." Race \& Class 49 (3):1-18.

Weaver, Lesley Jo, and Emily Mendenhall. 2013. "Applying Syndemics and Chronicity: Interpretations from Studies of Poverty, Depression, and Diabetes." Medical Anthropology 33 (2):92-108. doi: 10.1080/01459740.2013.808637.

Youdé, Jeremy. 2007. AIDS, South Africa and the Politics of Knowledge. Hampshire: Ashgate. 